\title{
YURII GRYGOROVYCH PTUSHYNSKYI (to the 90-th anniversary of his birthday)
}

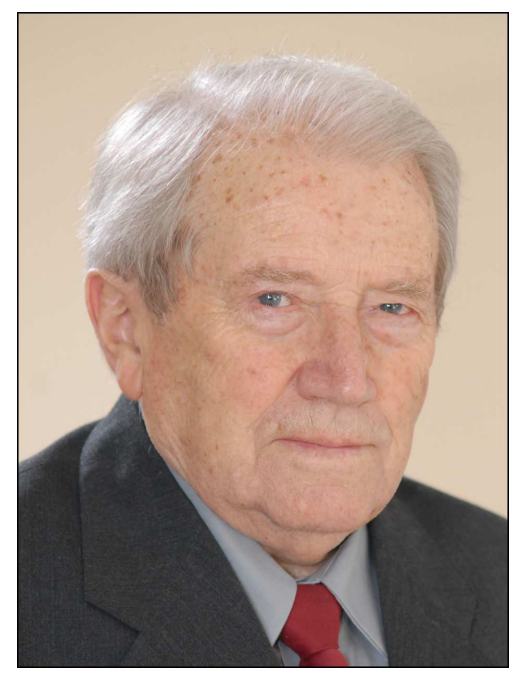

On November 29, 2017, the 90th anniversary of the birthday of a prominent Ukrainian scientist in solidstate surface physics Yurii Grygorovych Ptushynskyi takes place.

Yurii Grygorovych was born in Kyiv. His education at a secondary school was interrupted by the Great Patriotic War. In 1946, he passed the maturity examination, obtained a maturity certificate at an evening school for working youth, and entered the Faculty of Physics at the T.G. Shevchenko State University of Kyiv, which he graduated in 1951. The whole further scientific activity of Yurii Grygorovych was connected with the Institute of Physics of the Academy of Sciences of the UkrSSR [now, the National Academy of Sciences of Ukraine (NASU)]. Here, he finished postgraduate courses and passed a way from a junior researcher to the Head of the Department of Adsorption Phenomena and the Deputy Director on scientific work.
In 1955, Yurii Grygorovych defended his Ph.D. thesis on the research of diffusion processes in film-like oxide cathodes. By applying the method of labeled atoms, he obtained experimental data concerning the influence of main factors that determine the effectiveness of those cathodes. In 1971, Yurii Grygorovych defended his doctoral dissertation. In 1978, he was elected a Corresponding member of the NASU.

In his scientific activity, Yu.G. Ptushynskyi mainly focused his attention on the study of the adsorption interaction of atoms and molecules with surfaces of refractory metals. The fundamental results obtained by him are well known in Ukraine and abroad. Under his headship, the Department of Adsorption Phenomenon at the Institute of Physics of the NASU became one of the leading centers of the USSR in the field of surface physics and retained this status in independent Ukraine.

The performed researches with oriented surfaces of single crystals and the measurement of quantitative adsorption characteristics have helped to reveal their deep relationship with the electron structure of the surface. One of the unrivaled achievements of the team headed by Yurii Grygorovych became the development and creation of a unique physical installation that enabled the mass spectra of desorption products to be registered with a high accuracy in a wide temperature interval from 4.2 to $3000 \mathrm{~K}$. This equipment has been used in fundamental researches up to date. Those researches shed light on the dynamics of the processes of adsorption, desorption, catalysis, and corrosion. They revealed the role of the surface structure and quantum effects in those processes.

In the last years of Yu.G. Ptushynskyi's life, he and his disciples, including 3 Doctors of Sci. and $8 \mathrm{PhDs}$, obtained new fundamental results. In particular, when studying the low-temperature adsorp-

ISSN 2071-0194. Ukr. J. Phys. 2017. Vol. 62, No. 10 
tion of hydrogen and deuterium on single-crystalline surfaces of molybdenum, the isotope effect in the adsorption characteristics of gases was discovered, and the mechanism of the catalytic oxidation reaction of carbon monoxide at the platinum surface was studied. The latter problem is important from the viewpoint of the environmental protection.

An appreciable place in scientist's activity was occupied by the scientific-managerial and social work. Being the Head of the Department of Adsorption phenomena, which was created by him, and the Deputy Director of the Institute of Physics, Yurii Grygorovych was also elected a deputy of the District Council in the Moscow district of Kyiv. Furthermore, he was appointed a member of the People's Control Committee of the USSR; he was a member of the Scientific Councils of the Academy of Sciences of the USSR on physical electronics and physics, chemistry and mechanics of the surface, as well as a member of the editorial board of the Poverkhnost (Surface) journal.
The fruitful scientific, scientific-managerial, and pedagogical activities of Yurii Grygorovych was awarded many times. In 1998, he was awarded the title of Honored Worker of Ukraine in science and engineering. Yurii Grygorovych was a laureate of the State Prize of the USSR in science and engineering (1988). He won the A.F. Prihotko prize of the NASU (2003) and the State Prize of Ukraine in science and engineering (2008). He was decorated with the Order of the Red Banner of Labor and the Orders for Merits of the 2nd and 3rd degrees.

Yurii Grygorovych Ptushynskyi died on May 29, 2014. However, the blessed memory of him as a bright unordinary person, one of the most talented representatives of the world-famous Ukrainian school of physical electronics, an outstanding scientist, and a thoughtful teacher, will remain in the hearts of his disciples, who honorably continue his deed, as well as friends, colleagues, and everybody who knew him.

COLLEAGUES, FRIENDS, DISCIPLES 